\title{
Application of electrical resistivity tomography technique for delineation of gold mineralization in Bugai town, Birnin Gwari, Kaduna, North Western Nigeria
}

\author{
Nasir Khalid Abdullahi ${ }^{*}$, Muhamad Sani Ahmad ${ }^{1}$, Ango Abubakar ${ }^{2}$ \\ ${ }^{1}$ Department of Physics, Kaduna State University, Kaduna 800221, Nigeria \\ ${ }^{2}$ Kaduna State College of Education, Gidan Waya, Kafanchan 801147, Kaduna State, Nigeria
}

Corresponding Author Email: nkhalid26@yahoo.co.uk

https://doi.org/10.18280/eesrj.050105

Received: 22 May 2018

Accepted: 1 June 2018

\section{Keywords:}

electrical resistivity tomography, dipoledipole array, mineralization, silification, quartz veins, Bugai

\begin{abstract}
The aim of the present research is to provide an update of gold deposits models scattered in Bugai Village Birnin - Gwari Local Government Area of Kaduna State, through identifying basic geologic structures which act as host to mineralization, delineate zones of gold distributions and to map the spread and extend of the gold mineralization. Electrical resistivity method using the dipole-dipole array was applied and ten (10) parallel 2D profile data were collected manually each of length one hundred meters $(100 \mathrm{~m}$,) separated by ten meters $(10$ $\mathrm{m})$ and with minimum electrode spacing of three meters $(3 \mathrm{~m})$. The 2-D data were processed into 3-D data using RES2DINV computer inversion software for effective and accurate interpretation of the location for the gold deposit. Results from both 2D and 3D resistivity models show a variation in shape due to heterogeneous nature of mineralization within the study area at different depths. The mineralization within zones of elevated resistivity comprises of silification and quartz veining which is structurally controlled and follow a N-W and NE-SW orientations. The high resistivity anomalies at depth greater than five meters, (5 m) with well-defined patterns observed in the 3D resistivity model are related to the mineralization of gold bearing quartz veins. Geochemical analysis of rock samples collected at depth of five meters $(5 \mathrm{~m})$ which shows 124.79 and 1.77 concentration in ppm for gold and silver corroborated the result of the geo-electrical data. This research shows that electrical resistivity techniques can be applied to map the large scale stratigraphy and structure in which a gold deposit might be located.
\end{abstract}

\section{INTRODUCTION}

Earth scientists and Economists have long agreed that under the Nigerian soil are wealth and riches untold. But majority of Nigerians are wallowing in poverty. The Nigerian Extractive Industries and Transparency Initiative, NEITI report suggests that there are about 40 different kinds of solid minerals and precious metals buried in Nigerian soil waiting to be exploited. The commercial value of Nigeria's solid minerals has been estimated to run into hundreds of trillions of dollars, with 70 per cent of these buried in the bowels of Northern Nigeria [1]. With the dwindling of the price of petroleum products in recent times, and the abundance of Economic solid minerals in Northern Nigeria, it is urgent for Nigeria to exploit, explore and harness these abundant minerals for economic and sustainable development. Exploiting and harnessing the rich deposits of these economic solid minerals would open the gate for establishing small scale industries which would go a long way in curbing the unemployment rate in the country, thereby drastically reducing or curbing the menace of insecurity presently being experienced in the country most especially in the North. Kaduna state is richly endowed with about Nineteen (19) different economic solid minerals which can form the foundation upon which an industrialized economy can be built. Of the several minerals prospected for, gold is the most common, but what is witnessed today is that most of the exploitation is done by informal and in most cases illegal mining using very crude techniques with no consideration for the environment or human health. The search for mineral deposits, its exploitation, and processing as well as marketing to generate income by small scale miners is wide spread in North-western Nigeria. In Bugai town, the distribution of gold in the veins is erratic, making it difficult to estimate the average gold content and this has caused the artesian to dig indiscriminately (Fig. 1) searching for the veins. This indiscriminate digging for prospective holes for gold will in the future create an environmental problem. The application of imaging techniques in geophysics becomes necessary because for example many economically significant minerals - such as those in veins or pegmatite cavities are no larger than a few meters in diameter. Because of their small size, these deposits are easily missed with conventional mining methods (e.g., trenching or tunneling), and most geophysical techniques which are one-dimensional methods probe the subsurface in only one dimension, vertical or horizontal cannot produce the resolution (detail) necessary to detect them. Today, though, new methods of data acquisition and analysis (including sophisticated computer processing) enable some geophysical techniques such as Electrical resistivity to resolve geologic features that are as small as a fraction of a meter to a few meters in longest dimension and very shallow, within a few meters of the surface [2]. Electrical resistivity survey along the earth surface is a well-known geophysical exploration technique and due to its conceptual simplicity, low equipment 
cost and easy to use, the method is routinely used in mineral exploration [3-4]. It is environmentally friendly because the method does not induce adverse effect during and after use.

Birnin- Gwari is endowed with rich natural resources especially gold deposit. But the most unfortunate act on this development is that the gold mine is left in the hands of unprofessional miners (quark miners). These miners focused mainly on what to get now at the expense of the inhabitants (community) and the environment at large. Present study is to address the environmental problems through geophysical survey. In this research work, Electrical resistivity tomography technique was applied on 10 parallel profiles using the DipoleDipole electrode array in Bugai village, Birnin Gwari, Kaduna State, North Western Nigeria with aim of detecting and delineating gold mineralization zones.

The principle underlying the resistivity method is embodied in Ohm's law, which states that the current density at a given point is proportional to the electric field intensity at that point. Thus, Ohm's law gives the relationship between current density $\mathbf{J}\left(\right.$ amperes $/ \mathrm{m}^{2}$ ) and electric field intensity E (volts $/ \mathrm{m}$ ) as:

$J=\sigma E$

where $\sigma$ is the conductivity of the medium. Also $\mathrm{E}$ is the gradient of a scalar potential $\mathrm{U}$ (volts), i.e.

$E=-\nabla U$

Putting equation (2) into equation (1)

$J=-\sigma \nabla U$

From divergence condition,

$\nabla J=0$

Thus, from equation (3)

$\nabla J=-\nabla \cdot(\sigma \nabla U)=0$

Or

$$
\nabla \sigma . \nabla U+\sigma \nabla^{2} U
$$

For a homogeneous earth, $\sigma$ is a constant and since the derivative of a constant is equal to zero, then the first term in equation (6) vanishes hence,

$\nabla^{2} U=0$

Applying boundary conditions, equation (7) can be solved for specific cases. For instance, for a single current electrode at the surface of a homogeneous ground, equation (7) is expressed in spherical polar coordinates as

$\nabla^{2} U=\frac{1}{r^{2}} \frac{\partial}{\partial r}\left(r^{2} \frac{\partial U}{\partial r}\right)+\frac{1}{r^{2} \sin \theta} \frac{\partial}{\partial \theta}\left(\sin \theta \frac{\partial U}{\partial \theta}\right)+\frac{1}{r^{2} \sin ^{2} \theta} \frac{\partial^{2} U}{\partial \phi}$

For point current source, there is complete symmetry of current flow with respect to the $\theta$ and $\phi$ directions and the derivatives with respect to these directions are zero. Thus, equation (8) becomes $\frac{\partial}{\partial r}\left(r^{2} \frac{\partial U}{\partial r}\right)=0$

Integrating the equation twice gives

$r^{2} \frac{\partial U}{\partial r}=a \quad$ and $\quad U=-\frac{a}{r}+b$

where $\mathrm{a}$ and $\mathrm{b}$ are constant and $\mathrm{r}$ is the distance from the single current electrode. Since $U=0$ as $r=\infty$ then $b=0$

$U=-\frac{a}{r}$

The current flows radially outwards in all direction from the point current electrode and the total current crossing a sphere of radius $\mathbf{r}$ is

$I=4 \pi r^{2} J=-4 \pi r^{2} \sigma \frac{d U}{d r}=-4 \pi \sigma a=-\frac{4 \pi r^{2}}{\rho}$

Using equation (3) and equation (10)

$a=\frac{I \rho}{4 \pi} \frac{1}{r}$ So that in equation (10), by substitution gives

$U=\frac{I \rho}{4 \pi} \frac{1}{r} \quad$ Or $\quad \rho=4 \pi r \frac{U}{I}$

The equipotential which are everywhere perpendicular to the current flow lines will be spherical surface given by $r$ is equal to a constant.

The point current electrode of the three-point-system is located at the surface of the homogeneous isotropic medium and the air above having zero conductivity, the return current electrode is at a great distance. As in the previous case $b=0$ since $\mathrm{U}=0$ as $\mathrm{r}=\infty$

In addition $\frac{\partial U}{\partial Z}=0$ at $\mathrm{z}=0$

Since $\sigma_{\text {air }}=0$. In the present case, all the current flows through a hemispherical surface in the lower region.

Hence $a=-\frac{I \rho}{2 \pi}$ and $U=\frac{I \rho}{2 \pi} \frac{1}{r}$ or

$\rho=2 \pi r \frac{U}{I}$

Thus generally, the potential difference between 2 arbitrarily located points on the surface of a homogeneous isotropic ground is given by the following expression.

$\Delta \mathrm{U}=\frac{I \rho}{2 \pi}\left(\frac{1}{r_{1}}-\frac{1}{r_{1}}-\frac{1}{r_{3}}+\frac{1}{r_{4}}\right)$

where $\rho$ is the resistivity, $\mathbf{I}$ is the current and $r_{1}, r_{2}, r_{3}$, and $r_{4}$, are the inter-electrode distances as shown in Figure (2.)

From equation (11) the apparent resistivity can be solved for as;

$\rho_{a}=\frac{\Delta \mathrm{U}}{I} \frac{2 \pi}{\left(\frac{1}{r_{1}}-\frac{1}{r_{1}}-\frac{1}{r_{3}}+\frac{1}{r_{4}}\right)}$

The result is independent of the position of the electrodes and is not affected when the current and the potential electrodes are interchanged.

The resistance is calculated using Ohm's law: 
$R=\frac{\Delta \mathrm{U}}{I}$

where $\mathrm{R}$ is the resistance in ohms; $\Delta \mathrm{U}$ is the potential difference in volts; and $\mathrm{I}$ is the current in amperes.

The material parameter $\boldsymbol{\rho}$ which is the inverse of electrical conductivity $\boldsymbol{\sigma}$ is related to the resistance via a geometric factor $\mathbf{K}$ that is a function of the electrode configuration. The resistivity of the homogeneous ground can be calculated using, the relation

$\rho=\mathrm{K} \frac{\Delta \mathrm{U}}{I}$

where $\mathrm{K}=\frac{2 \pi}{\left(\frac{1}{r_{1}}-\frac{1}{r_{1}}-\frac{1}{r_{3}}+\frac{1}{r_{4}}\right)}$

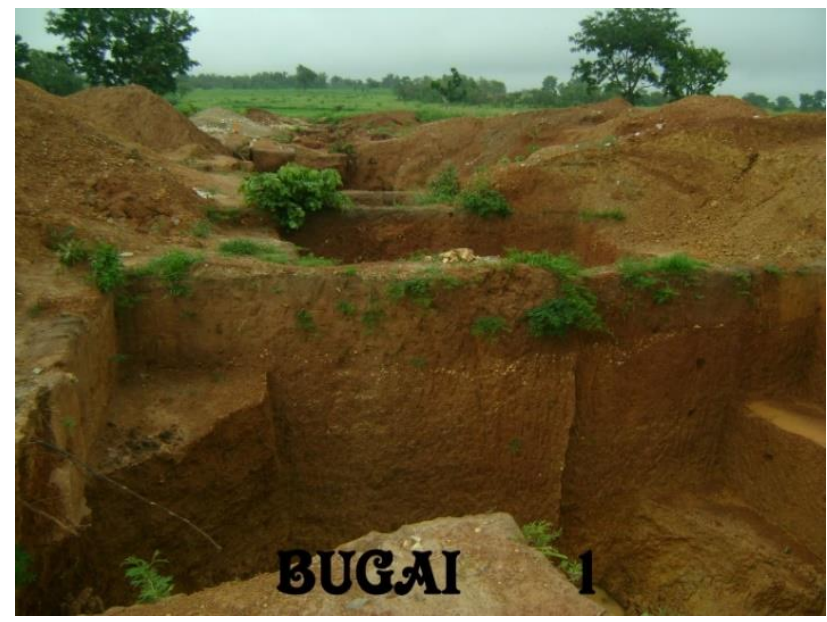

Figure 1. Dig pitches in parts of Bugai town by illegal miners

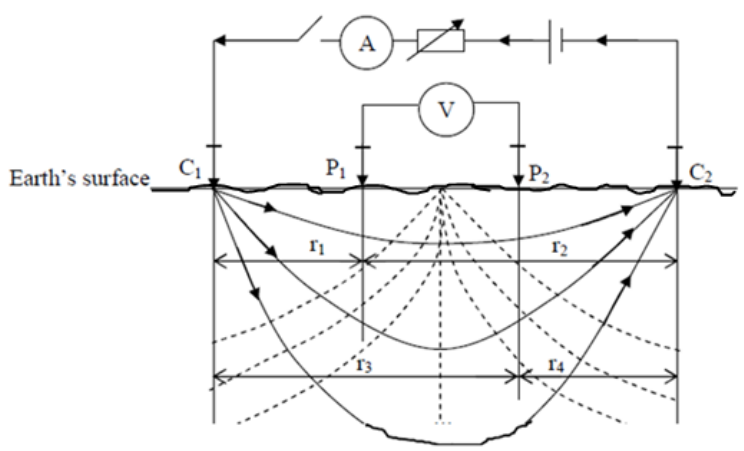

Figure 2. Current and Potential Distributions within Homogeneous Isotropic ground

\section{LOCATION AND GEOLOGY OF THE STUDY AREA}

The study area is Bugai in Birnin-Gwari Local Government Area of Kaduna State and is situated in the western part of Kaduna between latitude $12^{\circ}, 20^{\prime} N$ and longitude $90^{\circ} 0^{\prime} \mathrm{E}$. The regional geological settling of Birnin Gwari is divided into the basement complex and the schist belts [5]. The Basement complex is overlain by gently dipping cretaceous and younger sediments of the Iullemmeden basin in the North West and the Bida Basin in the South West [6] The Schist belts are divided into two main groups. The group in which the Birnin Gwari belt is assigned (Pan African Orogeny) has coarse-grained to fine-grained classic insignificant mafic igneous rocks. The fine-grained laminated sediments like phyllites and iron formation indicate quite water conditions [6]. The climate of the area is marked by two different seasons, the dry season and the rainy season. The dry season lasts from November to midApril while the rainy season lasts between 6-8 months starting from March. The temperature is cool during the rainy season and hot during the dry season. The peak of the rainy season is the months of August and September; the dry season on the other hand has its peak around February before the rainy season [7]. In the study area, highly weathered migmatites and gneisses are degraded to a material containing a very large proportion of kaolinite which occurs on the uppermost part of the weathered zone, and is associated with low permeability. The best prospect for groundwater, therefore, occurs in that part of the weathered zone below the kaolinized layer towards the base of the weathering zone (the active weathering front) where the rock has been broken down into sand size and larger fragments. The catchment area is drained mainly by rivers Damari, Kureta, Katakaki, Kusharki and Mariga which together are fed by a good network of tributaries well distributed all over the area [8].

\section{MATERIALS AND METHOD}

The field investigation involved application of 2D Electrical Resistivity (ER) technique. Ten (10) parallel 2D profile data were collected manually each of length one hundred meters $(100 \mathrm{~m})$ separated by ten meters $(10 \mathrm{~m})$ and with minimum electrode spacing of three meters $3 \mathrm{~m}$. The $2 \mathrm{D}$ geoelectrical resistivity imaging lines were measured with the aid of OHMEGA resistivity meter. In this survey, position of midpoint array using the Dipole- Dipole array (Fig 4) with $3 \mathrm{~m}$ interval between 33 electrodes was employed with each spread having a length of $100 \mathrm{~m}$. The measurement starts with a spacing of $3 \mathrm{~m}$ between $\mathrm{C} 1-\mathrm{C} 2$ and also between $\mathrm{P} 1-\mathrm{P} 2$ electrodes with a value of 1 for the $\mathbf{n}$ spacing factor until the end of the traverse lines. The factor $\mathbf{n}$ was then increased to 2 and the measurement is repeated along the traverse line while keeping the $\mathrm{C} 1-\mathrm{C} 2$ dipole pair spacing fixed at $3 \mathrm{~m}$.

This procedure was continued until the $\mathbf{n}$ spacing factor reaches a maximum value of about 6 , after which accurate measurements of the potential are difficult due to very low potential values. This procedure was followed for each of the traverses of A, B, C, D, E, F, G, H, I and J The apparent resistivity values for each profile were collated in a format acceptable by the RES2DINV inversion software. The computer code (RES2DINV) uses a nonlinear optimization technique which automatically determines a $2 \mathrm{D}$ resistivity model of the subsurface for the input apparent resistivity data [9]. The entire 2D resistivity models were later collated into $3 \mathrm{D}$ data set using the RES2DINV inversion software and the collated 3D data were then inverted using the inversion code, RES3DINV [10] For both the 2D and 3D data sets, the smoothness constrained least-squares inversion routine was employed. The final output displayed after the inversion was the inverse resistivity model showing the true depth and true formation resistivity that can be compared to geological crosssections. 


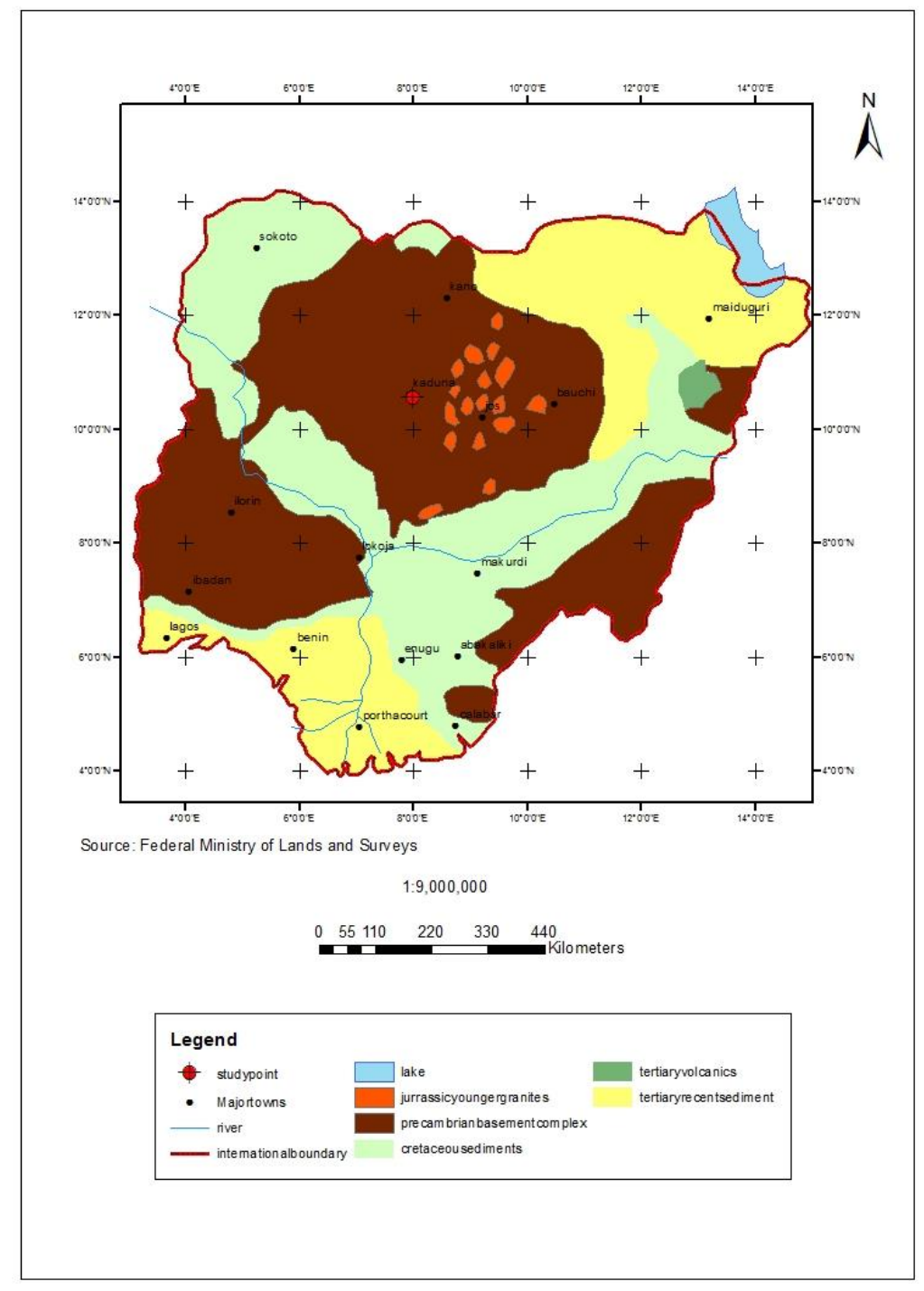

Figure 3. Geological map of Nigeria showing Kaduna state

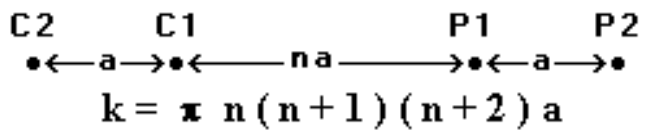

Figure 4. Dipole- Dipole array

\section{RESULTS AND DISCUSSION}

The 2D resistivity inversion model sections are presented in Figures 2 and 3, respectively. The RMS errors achieved in the inversion models were generally less than $5 \%$ except for some of the profiles that appears relatively noisy. Results from both 2D (Figs $5 \& 6$ ) and 3D resistivity models (Fig 7) show resistivity models varying in shape due to heterogeneous nature of mineralization within the study area at different depths. Basically, the 2D resistivity models depict the fairly heterogeneous geology of the area comprising quartz vein or quartzite. These anomalies occurred within zones of elevated resistivity that may represent silification and quartz veining. This is corroborated by the abundance of quartz vein is the area (known as JIRGI by the locals) from the several artisanal pits and trenches in the study area. The heterogeneous pattern and trends defines by the anomalous zones suggest that the mineralization is structurally controlled and fallows $\mathrm{N}-\mathrm{S}$ and NE - SW orientations. Quartz veins signatures are identified by high resistivity (>600 ohm-m) anomalies both at shallow and greater depths but the anomalies at shallow depths have no specific trends and are partly related to effect of weathered soil derived from the weathering and attention of the sulphite bearing quartz veins. Figure 4 shows the $3 D$ resistivity model which reveals significant resistivity anomalies with a general trend indicating a low resistivity and high resistivity along the various depths $(0.00 \mathrm{~m}-1.05 \mathrm{~m}, 1.05 \mathrm{~m}-2.26 \mathrm{~m}, 2.26 \mathrm{~m}-$ $3.65 \mathrm{~m}$ and $3.65 \mathrm{~m}-5.24 \mathrm{~m})$. It is observed that, the effect of top weathered soil becomes obviously less at greater depth $(3.65 \mathrm{~m}-5.24 \mathrm{~m})$. The high anomalies at greater depth with well-defined patterns observed in the $3 \mathrm{D}$ resistivity models are related to the mineralized gold bearing quartz veins.

\section{GEO-CHEMICAL ANALYSIS OF ROCK SAMPLES}

Geochemical analysis of rocks sample collected at $5 \mathrm{~m}$ depth was conducted at Nigerian Geological Survey Agency, Kaduna State, Nigeria and the laboratory results showed that concentration of gold in one of the rock samples (Fig 8) is $124.79 \mathrm{ppm}$ while that of silver is $1.77 \mathrm{ppm}$. 


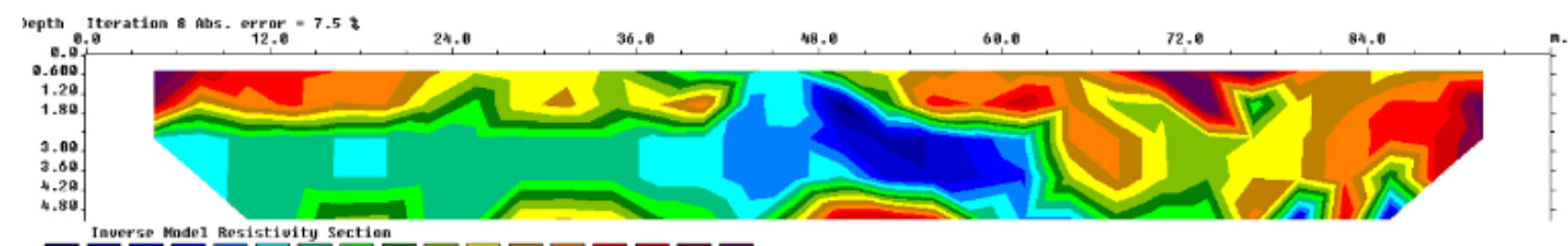

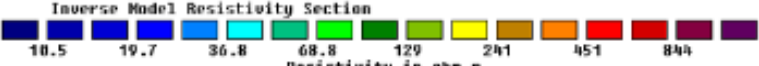

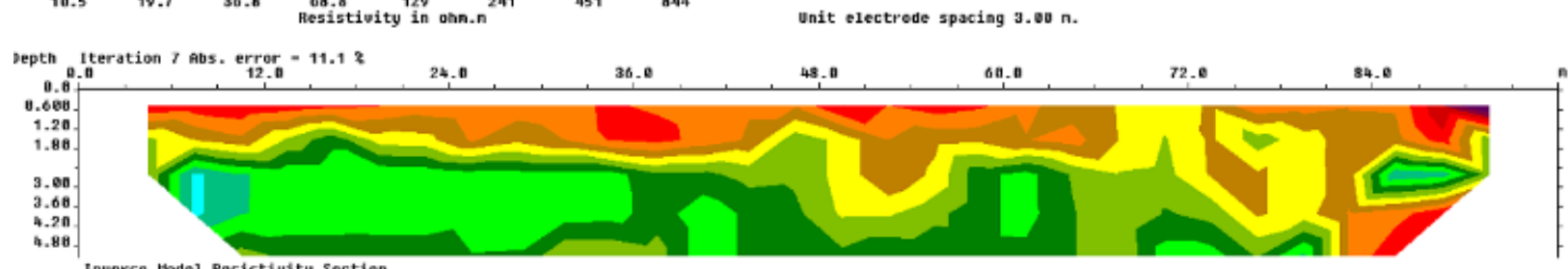

$\square_{2.12}^{\text {Inegrse Hode1 Resistivity Section }}$

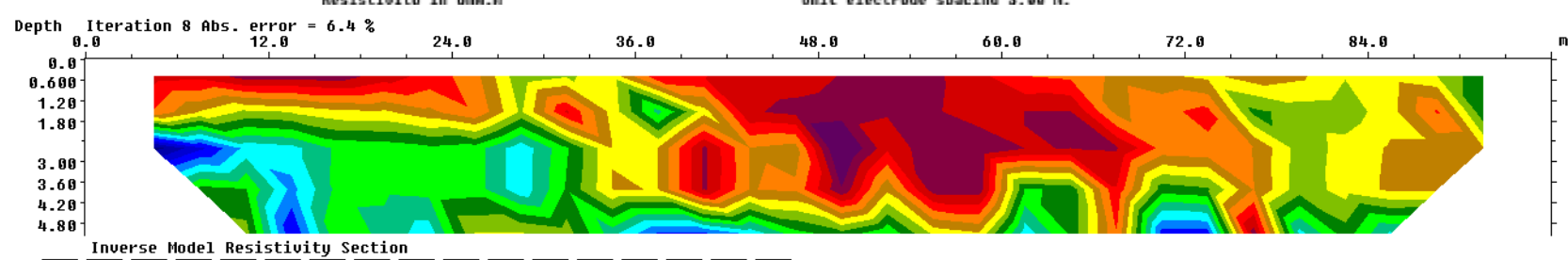

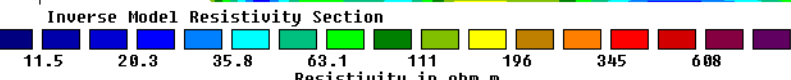

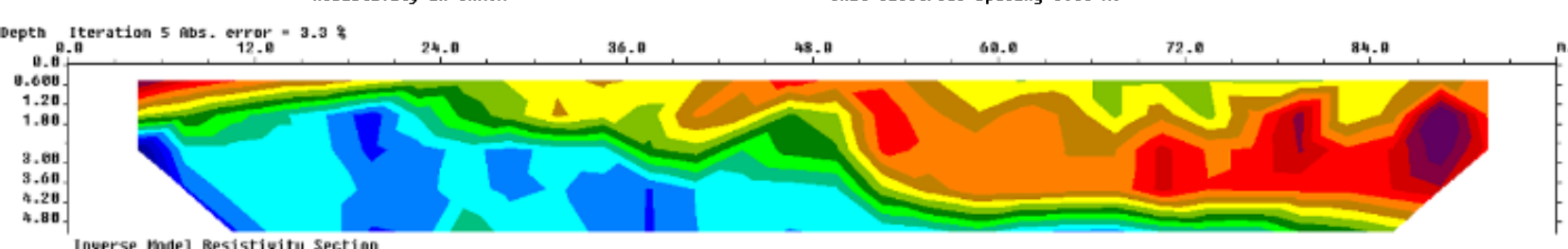

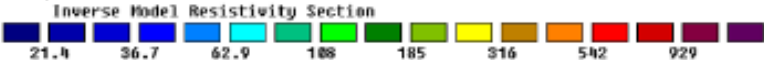

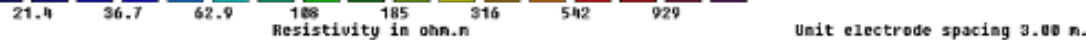

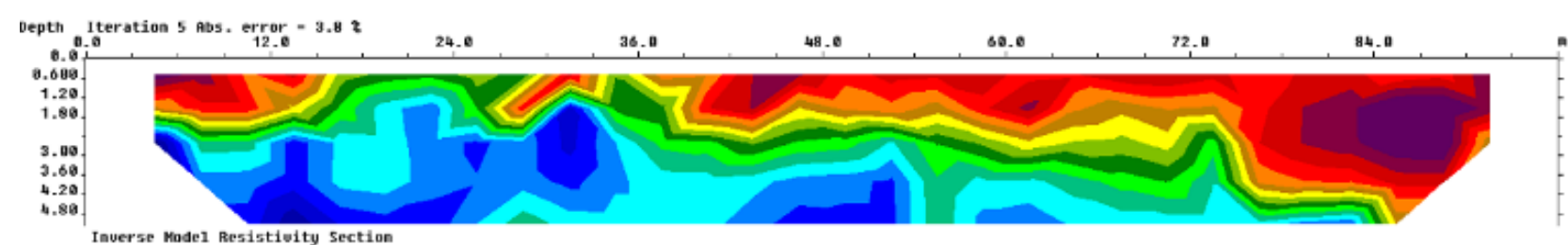

${ }_{25.2}^{\text {Inverse Mode1 Resistivity Section }} \square_{39.5} \square_{61.9} \square_{97.0} \square_{238} \square_{373} \square_{584} \square_{152}$

Figure 5. 2D Resistivity models along profiles A-E

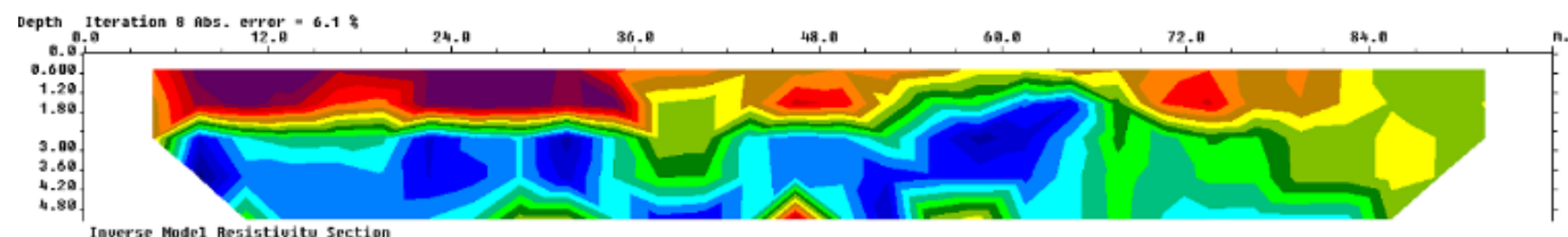

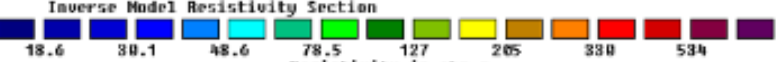

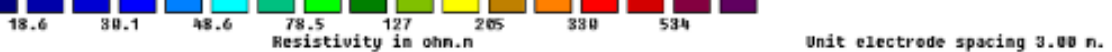

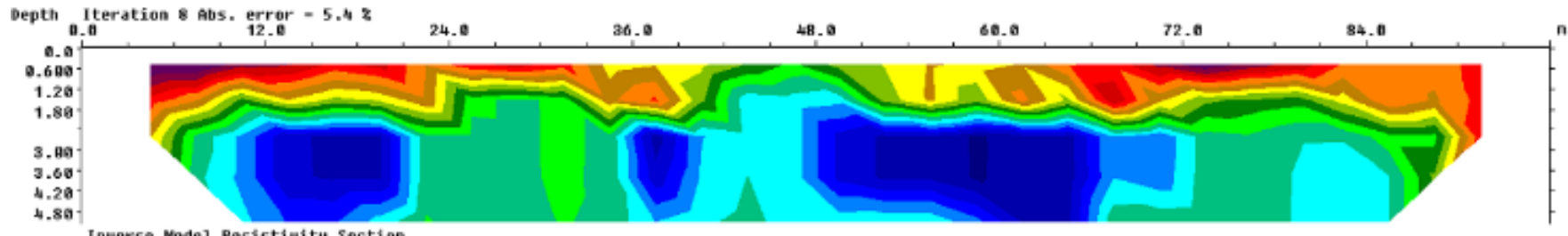

$\square_{38.8}^{\text {Inverse Mode1 Resistivity Section }} \square_{54.3} \square_{77.7}^{111} \square_{228} \square_{326} \square_{467} \square_{159}$

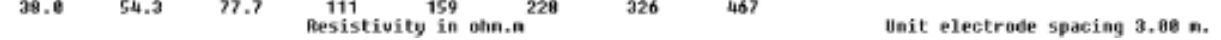




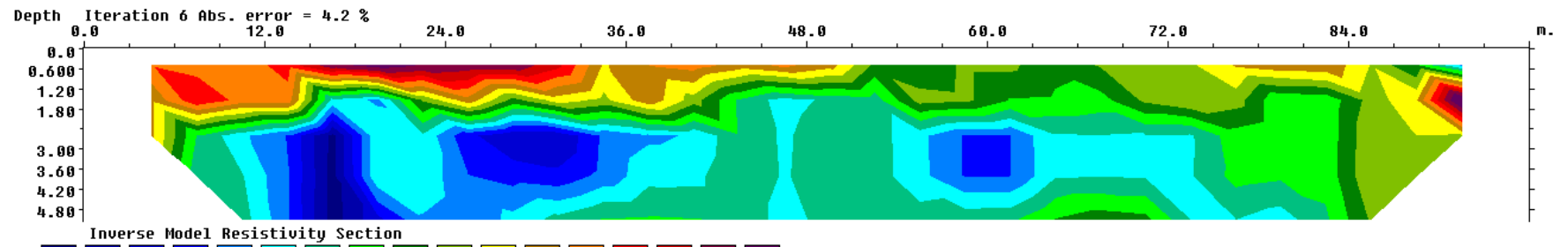

Inverse Model Resistivity Section

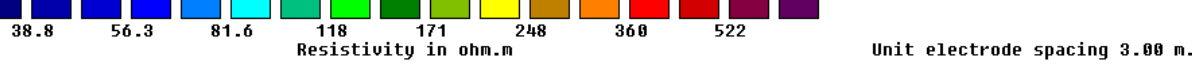

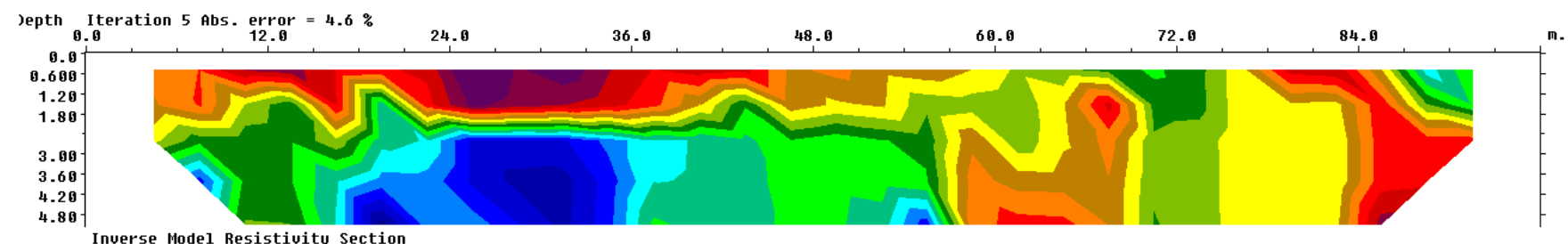

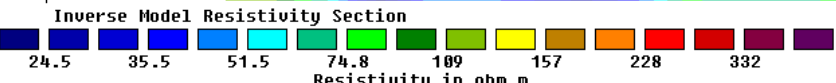

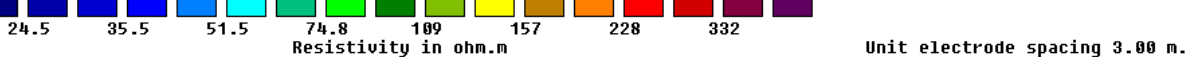

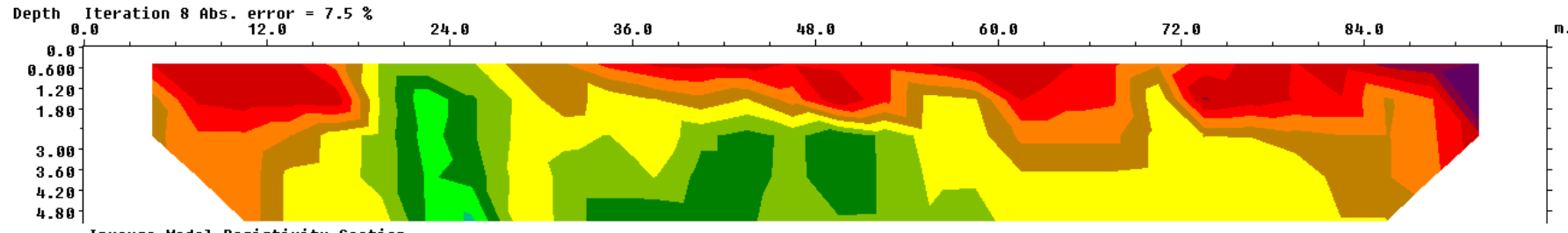

Inverse Model Resistivity Section

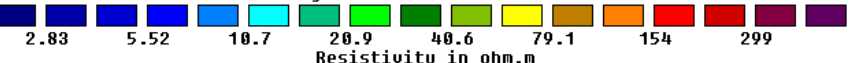

Figure 6. 2D Resistivity models along profiles F-J
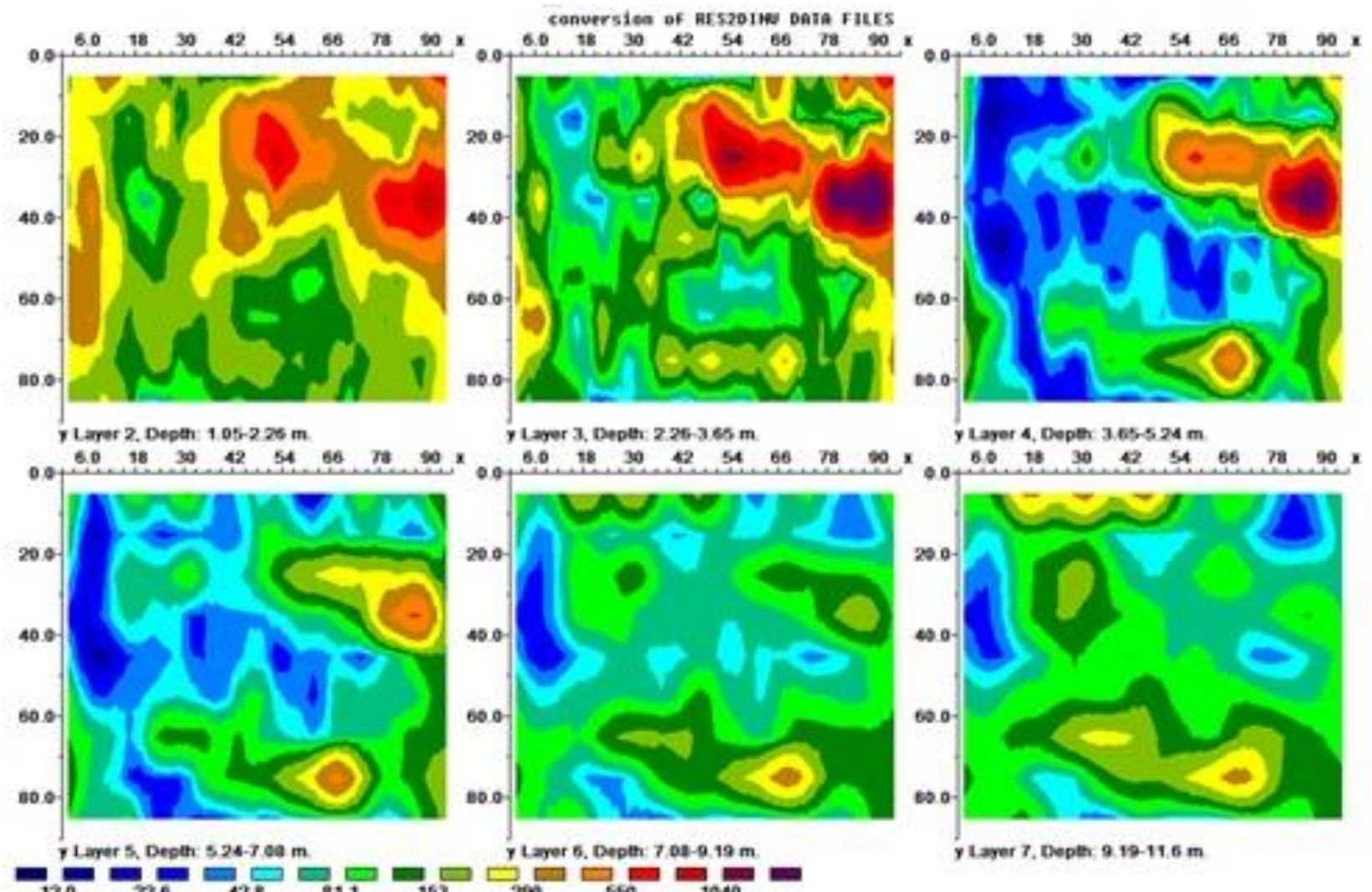

ए

X Unit Electrede spacing 3 on. Y Unit Eectrode Spacing 10 ov. Aeration 8 - Ras Eree $10.7 \mathrm{X}$

Figure 7. 3D Resistivity model 


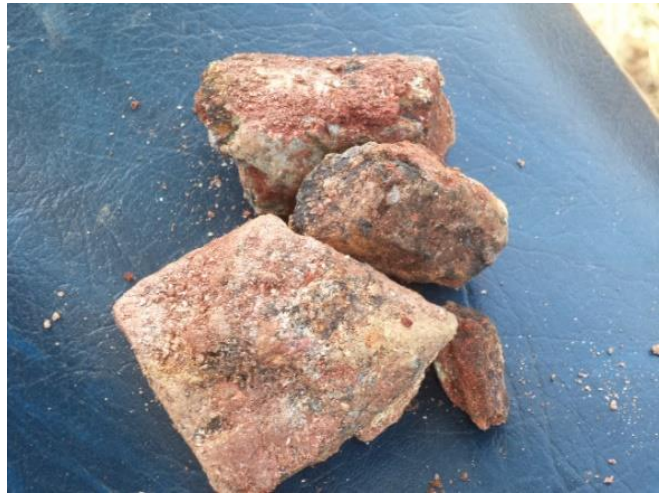

Figure 8. Rocks samples collected for geo-chemical analysis

\section{CONCLUSION}

Electrically resistivity imaging was successfully carried out at Bugai town in Birnin - Gwari area of Kaduna State, North western Nigeria. Results from both the 2D and 3D resistivity models reveal a heterogeneous nature of mineralization within zone of elevated resistivity that may represent silification and gold bearing quartzite vein. The results of the survey indicated $\mathrm{N}-\mathrm{S}$ and $\mathrm{NE}-\mathrm{SW}$ treading mineralized zones embedded in rocks with resistivity value greater than $600 \mathrm{ohm}-\mathrm{m}$ occurring at depth greater than $5 \mathrm{~m}$. Geochemical analysis of rock samples collected at $5 \mathrm{~m}$ depth complimented the geo-electrical results. This research shows that electrical resistivity techniques can be applied to map gold mineralization when the source body lies flatly in the study area.

\section{ACKNOWLEDGEMENT}

The authors are grateful to the Administrator of Birnin-
Gwari Local Government Area for approval and facilitating the collection of the geophysical data.

\section{REFERENCES}

[1] Vanguard Newspaper.www.vanguardngr.com, accessed on Feb. 26, 2018.

[2] Frederick AC. (1997). Applications of geophysics in gemstone exploration. Gems \& Gemology 33(1): 4-23.

[3] Sultan AS, Salah A, Fernando MS, Ahmad SH. (2009). Geophysical exploration for gold and associated minerals, case study: Wadi El Beida area, South Eastern Desert, Egypt. Journal of Geophysics and Engineering 6(4): 325-335.

[4] Jong-Oh P, Young JY, Hee J K. (1991). Electrical resistivity surveys for gold-bearing veins in the Yongjang mine, Korea. Journal of Geophysics and Engineering 6(1): 79-90

[5] Russ W. (1932). The Birnin-Gwari Gold field. Report of Geological Survey of Nigeria 1931 part 11A.

[6] Garba I. (2002). geochemical characteristics of the gold mineralization near Tsohon Birnin-Gwari, NorthWestern Nigeria. ChemErde-Geochem 62: 160-170. https://doi.org/10.1078/0009-2819-00008

[7] Keay RWJ. (1953). An Outline of Nigerian Vegetation. Lagos Government Printer.

[8] Omorinbola EO. (1986). Pattern and persistence of groundwater level fluctuation in humid tropical regolith: A case study from Nigeria. GeoJournal 12(4): 423-431.

[9] Griffith DH, Baker RD. (1993). Two -dimensional resistivity imaging and modelling in areas of complex geology. Journal of Applied Geophysics 29: 211-226.

[10] Loke MH, Barker R.D. (1996). Rapid least-squares inversion of apparent resistivity pseudo-sections by a quasi-Newton method. Geophysical Prospecting 44: 131-152. 